\title{
DISCUSSION CIRCLE FOR THE TEACHING-LEARNING OF STATISTICS
}

\author{
MARCOS N. MAGALHÃES \\ University of São Paulo, Brazil \\ marcos@ime.usp.br \\ MARIA CECILIA CAMARGO MAGALHÃES \\ Pontifical Catholic University of São Paulo, Brazil \\ cicamaga@gmail.com
}

\begin{abstract}
Conceptual appropriation is central to the teaching-learning and development processes. The intellectual stage is expressed by writing, verbalization and the use of the object under construction, among other means of expression. This paper discusses the conceptual appropriation by means of the creation of collaborative situations in which the argumentative language mediates the construction of knowledge. Supported by Vygotsky's cultural-historical theory, Discussion Circle is an activity that consists of presenting some conceptual questions for the class to discuss in small groups initially, and then in a larger group, at a general meeting. Hence, we present the central ideas and theoretical support for the development of this activity and comment on a practice that took place during a course of Basic Statistics, part of the Teaching Program in Mathematics. Results indicate the conceptual development of students, which allows for the improvement of elementary school mathematics' teacher education in terms of statistics studies, which is a strategic matter of importance for the broadening of society's knowledge about this area.
\end{abstract}

Keywords: Statistics education research; Basic statistics; Active participation; Collaboration; Discussion circle; Questioning

\section{INTRODUCTION}

This paper aims at discussing the organization and development of Discussion Circle, a teachinglearning activity that is based on cultural-historical theory and seeks to enhance the active, collaborative and critical participation of students in a course of Basic Statistics for future Mathematics teachers. The course is part of the teaching undergraduate program in mathematics at the University of São Paulo, Brazil. The question we sought to answer through the data interpretation process was, "How does the activity contribute to the development of statistical concepts by students?"

In a globalized world, the education of the youth needs to allow them to become fully integrated in society. Technological changes, ever so rapid, have an impact on the teaching-learning process and evoke a number of reflections for the school. Electronic devices capture attention and nearly hypnotize users, leading many students to establish a solitary routine, despite being connected through social networks. In such a complex context in which education is developed, the need to bring changes to the school environment is urgent, in order to allow for the understanding of theories that support the teaching-learning process, the roles played by students and teachers, the organization of language, as well as the relations within the school and their role in educational results. Promoting interaction between peers and the enhancement of the critical-collaborative involvement of students in classroom activities is a challenge that still thrives.

School organization is, as pointed out by Gee (2000, p. 42), usually disconnected from the transformations that society undergoes, rather it is supported by systems that are based on an authoritarian and pyramidal hierarchy, on individualism, and on teacher's control over what students think and say. Traditionally, this organization is unable to secure a kind of education where all students can participate collaboratively, being active and critical in their construction and transformation of society. 
By the same token, Kalantzis and Cope (2008) stated that schools need to create pedagogical practices that are organized for the critical appropriation of school content in a way that there is a clear relation to its use in society. Besides, Freire (1978) says there is a need to change the language from saying to creating; from individualism to collaborative organizations; and from teacher's narratives to collaborative actions that involve students and teachers. In other words, the change must be seen in the constitution of a school that is not encapsulated solely in school content, but considers the larger society.

The National Curricular Parameters - PCN (Brazil, 1997, 1998, 2000, 2002) and the Common National Curricular Basis - BNCC (Brazil, 2018) are a group of official documents that recommend for the organization of school content (elementary, mid, and high schools). They specifically point out that mathematics should include content of probability and statistics. Thus, in the Brazilian context, the mathematics teacher is responsible for teaching these topics and are supported by the pre-service education that they receive during their undergraduate program.

Those who take teaching degree courses in mathematics will attend one or two basic courses on statistics. Content usually includes data analysis, probability, model/random variables and inference. We ought to mention that, in Brazil, there are several mathemtics teachers in basic education (elementary, mid, and high schools) who have degrees in connected areas such as physics and engineering. In such cases, it is common to see that curricula also include topics in statistics. Depending on the tertiary institution, the courses of statistics offered will have certain procedures to follow and expected results, and these are influenced by the previous knowledge that students may have, by the objectives of the course, and by the education that the professors and lecturers who are responsible for the courses may have received. In general, in public universities - regardless if state or federal institutions-professors/lecturers that are responsible for the courses have doctorate degrees in statistics, which should guarantee the correct discussion of the projected content. In any case, several other matters are needed in order to guarantee that learning by undergraduate students is effective. Some will be considered throughout this text.

Discussion Circle is an activity that is organized with an initial part for discussion in small groups. This is followed by a general discussion in order to systematize the reflections carried out by the groups. The objective here is to promote collaborative contexts between students allowing their development with regards to a specific topic that composes the content projected for this course. The culturalhistorical theory (Vygostsky) supports the reflection about the results of the activity that we present in the paper. The activity was audio recorded in the groups and audio/video recorded in a general meeting.

\section{THEORETICAL FRAMEWORK}

In this section, we discuss concepts referring to teaching-learning and development as they are understood when based on the cultural-historical theory (Vygotsky, 1934; 1930). Besides, we also discuss matters pertaining to the teaching-learning of statistics.

\subsection{CULTURAL-HISTORICAL THEORY}

We begin with a short definition of concepts that are related to the construction of relations that allow for the critical-collaborative movement. For Vygotsky, the teaching-learning and development processes were considered social, collective, and collaborative constructions, rather than individual enterprises. He emphasized the importance of development in relation to learning and of collaboration with others, stating that these are mediated by language from the first moments of life. Vygotsky's objective was to explain that for development it is necessary to create contexts in order to transform totalities and not specific contents. In this sense, the Zone of Proximal Development (ZPD) is the space that lies between what participants are and what they are in the process of becoming (Holzman, 2002; Stetsenko, 2017), a zone of creative action, a practical-critical transformative activity in which collaboration and criticality are key elements.

Based on the discussions carried out by Vygotsky $(1930,1934)$, researchers who work with his ideas nowadays (e.g., Stetsenko, 2017; Magalhães, 2009, 2018; Ninin \& Magalhães, 2017) among many others, state that language is a central element to mediate the collaborative organization of contexts for learning and development of scientific concepts in the classroom. This is the case of language that is 
organized argumentatively, which implies collaborative relations that focus on socio-historical contradictions that are constituted as part of our experiences. The idea is based on the critical understanding of how classroom relations are structured, of the theories that support teaching-learning and development matters, as well as of how the roles played by teachers and students are organized in ways to allow for mutual relationships in posing and solving problems in the construction of knowledge (Freire, 1978).

Also, according to Vygotsky $(1930,1934)$, collaboration is the process of constructing with others, a process in which participants work together in order to understand and transform the world and, in this process, they transform the specific collective contexts of action, the society and themselves. As stated by Stetsenko (2017), moving Vygotsky's discussions forward, "human development is a collaborative project of people who are changing and co-creating the world" (p. 19). Collaboration, therefore, always involves contradiction between the several senses of participants as to the object under discussion since these were socio-historically constituted, through many diverse life experiences. In fact, it is the concept of contradiction that allows the focus to be kept on collaborative discussions mediated by argumentative language.

The relationship with others in the school context is mediated by and within language, being central to the construction of scientific concepts. As underlined by Ninin (2018, p. 53), it occurs by mediation of the concepts that have already been appropriated, and is characterized by generalization, in relationships between participants of a given interaction. Based on Vygotsky, this collaborative space created is a ZPD and, according to Ninin (2018), it can "provoke transformations that lead the subject to bring to the zone of real development that which can be seen at a distance" (p. 55). This last author also points out that the discussion is motivated by questions and answers from peers and the professor is the potential to promote the development of a concept that students potentially manage.

Considering questions that are constituted in activities of dialogic actions by means of the use of language, Ninin (2018) mentions three central dimensions for the act of questioning: Pragmatic, Epistemic and Argumentative. The author mentions that, in school learning situations, there are overlaps of question dimensions, but the possibilities of ZPD creation occur when the argumentative dimension is present. In this context, questions may be pragmatic-argumentative, epistemic-argumentative, or pragmatic-epistemic-argumentative, since it is argumentation that allows for the dialogic expansion, valuing the space of discussion and collaboration in scientific knowledge production. Table 1 shows the main characteristics of each dimension.

\section{Table 1. Dimensions of the act of asking questions: Characteristics}

\footnotetext{
Pragmatic Conditions created by participants' own action contexts in order for the activity to take place.

Subject matter validated by the group.

Possibility of discussing the subject in the group.

Participants' access to the subject.

Priority to contextual elements within the utterance episode.

Possibility for diverse utterance deliveries, based on the social position occupied by participants as well as their culture.

Epistemic Concepts and definitions retrieved from the very utterance moment and from discursive actions.

Reasoning means that are typical of the field of knowledge, favoring spontaneous and scientific knowledge relation.

Reasoning progress/expansion.

Overcoming of epistemological obstacles.

Argumentative Stimulation of reasoning processes that prioritize insertion of point of view, diverging ideas, and arguments.

Establishment of doubts in order to provoke argumentative movements and dialogical expansion.

Construction/reconstruction of arguments based on linguistic and discursive resources of dialogical expansion rather than those of dialogical contraction.
} 


\subsection{TEACHING-LEARNING OF STATISTICS}

The activity that is discussed in this paper was carried out in a course whose objective was basic education in statistics. According to Gal (2002), this encompasses data understanding, graphic and table analysis capacity, as well as the understanding of basic ideas of probability and inferencing. It is important that the content that is discussed may be reflected upon in teaching terms so as to adequately prepare the future teacher, as indicated by Garfield and Ben-Zvi (2008). According to Groth (2007), statistics is not a branch of mathematics and the statistical knowledge for teaching includes mathematical and non-mathematical knowledge. The author still suggests efforts are needed to reduce the artificial separation between the teaching of statistics in schools and the discipline of statistics.

Along these lines, Ponte and Noll (2018) presented a comprehensive discussion about statistics teacher education that covers all levels and emphasize three challenges: knowledge of content, classroom actions, and acquaintanceship with statistics software. According to the authors, the development of statistics teachers is an incredibly important task that needs to be taken seriously by the community of statistics education. They contended that teacher knowledge, as well what they do during their lessons, impact their students' learning.

Several Brazilian authors have reflected about the development of basic courses on statistics. Campos et al. (2011) proposed using what is known as critical statistics education in these courses, enabling for a greater involvement and learning by students. From their teaching experiences, Porciúncula and Samá (2015) suggested the use of projects for the construction of statistic knowledge and indicate the following phases: 1) Thematic definition and group constitution; 2) Definition of the question to be investigated, the population/sample and the design of questionnaire; 3) Data collection, organization and analysis; and 4) Publication of results. According to the authors, the projects assist in the construction of a space coexistence, boosting cooperation, autonomy and criticality among students. Samá et al. (2019) supported the idea that during their education, the teaching undergraduate students experience active methodologies that may support their actions as teachers. They explained three such methodologies, commenting their applications for students of teaching courses in three different universities. More specifically, in terms of mathematics teacher education, Barbosa et al. (2016) presented a methodological tutorial with activities for teachers of mathematics to improve their education in terms of discussion of statistic concepts with high school students. The authors, supported by Wild and Pfannkuch (1999), proposed that investigative cycles be carried out with Planning, Analysis and Conclusion (PAC) and discuss the use of software R. Based on the cultural-historical theory (Vygotsky), Magalhães and Magalhães (2014), described four activities (anticipated reading, writing conceptual connections, data analysis and didactic preparation) and discussed the learning and development results with reference to prior delivery of the same course. Schreiber and Porciúncula (2019) examined the contributions of what is called learning projects for the education of future mathematics teachers. They stated that, in their experience, the undergraduate students (future teachers) constructed knowledge related to descriptive statistics and pedagogical practice, which demonstrated interest in developing these projects in their future classrooms.

\section{METHODOLOGY}

\subsection{RESEARCH CONTEXT}

There were important improvements in Brazil in the area of teacher education, from 2002 onwards, especially in terms of the expansion of the number of universities and federal institutes and initiatives, such as the national minimum wages for teaching professionals. As of August 2016, the area was shaken by financial cuts and other disqualifying attacks. Teachers from several educational levels-who had already been facing many difficulties, especially those working with basic education (elementary, mid, and high schools) - now have an even more unfavorable perspective in terms of working conditions. The teaching profession may now broaden its already high lack of prestige within the Brazilian society, and this may therefore hinder even further the view that young people have of this field of work as a profession that is not very attractive.

The University of São Paulo is the biggest university in Brazil, accommodating today 60 thousand undergraduate and 30 thousand graduate students. It is a public university maintained by the state 
government of São Paulo and does not charge annuity. There are six campuses throughout the state of São Paulo, the largest of them being housed in the capital city, where the Mathematics and Statistics Institute (IME) is located. IME offers five undergraduate degrees (Computer Studies, Statistics, Mathematics, Applied Mathematics and Computer Applied Mathematics) and one teaching degree in Mathematics, operating in two periods, during the day and at night.

Reflecting the mentioned context, data from the 2019 Foundation for Tertiary Entrance Examination at the University of São Paulo - Fuvest (https://acervo.fuvest.br/fuvest/2019/), show that the candidate/vacancy ratio for the teaching degrees is reasonably low. For example, for the career that included teaching of Mathematics and Physics (at USP situated in São Paulo, capital city) there was an interest of 3.59 candidates per vacancy. For comparison purposes, we highlight that the lowest search was seen in the teaching degree in Geosciences and Environmental Education, which had 1.43 candidates per vacancy, and the highest was Medicine (in São Paulo, capital city) with 115.24 candidates per vacancy.

The teaching degree in Mathematics at IME-USP has two compulsory courses of statistics in its curriculum. During the day, these courses are intended for students entering the course (freshman/women) and, in this paper, we are referring to students taking Statistics for Teaching I (Estat I), offered in the first semester of 2019. This course's program encompassed the topics: Combinatorial Analysis, Descriptive Statistics, Probability and Discreet Random Variables (one and bidimensional). The mathematical level of the course was compatible with several books on basic statistics published in the country, and the coursebook adopted was that by Magalhães and Lima (2015).

In 2019, the course had 71 students enrolled during the day, most of which were freshman/women, who initiated their university degree in 2019. The final result for the course was an average calculated from tests, tasks, assignments, and individual and group activities. Several activities are carried out in groups with a view to promote students' participation. In particular, the assignments of Data analysis and Didactic preparation, were similar to the ones described by Magalhães and Magalhães (2014), had enthusiastic participation on the part of students. One of the activities carried out in 2019 is the object of this paper and will be described in the next subsection.

\subsection{DISCUSSION CIRCLE}

As we have pointed out, Discussion Circle is organized by means of two phases of discussion regarding the concepts of one or more topics in statistics. In the first phase, the groups of students discuss a question posed by the professor and, following that, the second phase is composed of a whole class discussion in a U-shape classroom organization. In this moment, the students have the opportunity to relate and reflect upon the answers provided by all the groups. The activity may vary in duration as per the number and complexity of items asked, the size of the class and students' familiarity with the actitivy. It is the role of the professors, with content knowledge and classroom experience, to assess the time that will be necessary, but we initially suggest something between 10 and 15 minutes for each item asked, which is valid both for the group and whole class discussions.

Whilst carrying out the activity, students should have room during the group phase to exchange ideas and collaborate in the construction of an answer to be written and presented in the general discussion. Therefore, it is important that the groups be of an adequate size to allow for a balanced contribution of all participants in the time that they have available to carry out the activity. In general, the experience recommends between three and five students per group. For the general discussion, there are some procedural alternatives that can be used depending on the number of items to be discussed and the number of students in class. For example, the starting point may be the answers provided by some groups, while the others are requested to comment, or the discussion can be open for whichever student wants to take the turn, while all of them are requested to provide their points of view and opinions. By using their knowledge of the class, the professor can guide them in order to better conduct this part of the activity. Another important aspect is to interrupt the silencing of students and the focus on the professor's speech, rather common features in large classes in the field of mathematics.

Discussion Circle is an activity that integrates a number of initiatives developed by the professor of the course of Estat I, seeking to allow the students the opportunity to verbalize and write down their understanding about the concepts that are discussed in class. Note that this is corroborated in the Guidelines for Assessment and Instruction in Statistics Education - College Report (GAISE, 2016), 
which is written with the support of the American Statistical Association (ASA). The report presents six recommendations for the teaching of statistics at the undergraduate level, two of which refer directly to the activity discussed in this paper: focusing on the conceptual understanding and promoting active learning. Discussion Circle activity is also consistent with the teaching model Statistical Reasoning Learning Environments (SRLE) proposed in Garfield and Ben-Zvi (2008) to develop students' statistical reasoning. Along the same lines, the inclusion of argumentative items in assessments is important, as highlighted in Magalhães (2019). Besides allowing the professor a more realistic outlook of how learning is taking place, these initiatives can assist in the planning of future actions and enhance the conceptual understanding, by students, of the topics encompassed in the course.

\subsection{DATA PRODUCTION AND SELECTION}

The Discussion Circle activity, carried out in the course of Estat I in 2019, involved items about the relationship of random variables, such as joint probability and independence. The proposed items, presented on Table 2, were the ones chosen, for being related to the ideas that are frequently likely to be misinterpreted. Thus, the activity was carried out also with the intention of summarizing some of the main conceptual aspects involved. For a reference on reasoning about data that includes covariation and association between variables, see Biehler et al. (2018).

\section{Table 2. Discussion circle items}

\footnotetext{
1. What are the conceptual differences between independence of events and the independence of random variables?

2. Can we obtain the probability joint function of two random variables if we know the respective probability marginal functions?

3. What do you think of the sentence: "Variables are non-correlated, and therefore are independent"?
}

Source: Designed by the authors

At the beginning of the activity, the professor explained the procedure to follow, handed out the text with the items to be answered, and requested the groups be formed. Students were instructed to provide answers without consulting the books or notebook notes. The expectation was for the students to use the conceptual information appropriated during the discussions carried out in previous lessons. Besides the professor, 43 students took part in the activity, divided into 9 groups, most of which followed the recommended number of members of three to five, one had six members, and another had seven. The activity took around 50 minutes to be completed, 30 minutes was used in the first phase (groups) and 20 minutes for the second (whole group discussion). Data obtained refer to the answers written by the students, the audio recordings of group discussions, as well as audio and video recordings of the whole group discussion.

In order to avoid extending this paper too much, we will focus on the analysis of Item 3 (Table 2), which was more widely debated among the students. For similar reason, we will analyze the groups in which most participants interacted collaboratively in order to produce the answer. We will therefore analyze five of the total nine groups.

The item chosen for analysis provides a good overview of the characteristics aimed at with the activity, that is, to promote greater discussion among students in order to attain progress with regards to conceptual development. Note that the question asked in the item was thought provoking and explored the different possibilities of interpretation of a word - which may vary according to the technical scientific or informal (social/common sense) context. Learning and development takes place when the student manages to connect statistical concepts with the real world, that is, the responses reflect the language used outside of the school environment.

Item 3 assesses students' understanding of the concept of linear correlation, previously discussed in class. This question was worded informally on purpose, thus mimicking the way that it is often used in people's conversations to refer to the relationship between any couple of variables, regardless of whether they are quantitative or not. Note that, bearing in mind the statistical sense discussed in the course, non-correlation indicates that there is no linear correlation between two quantitative variables, 
and this does not guarantee their independence, since they could have another type of relationship (quadratic, exponential, etc). Hence, the item also seeks to assess how students deal with duality between oral (and written) language associated with the concept, in both the technical and the informal usage.

Therefore, the item has components of two of the dimensions mentioned by Ninin (2018). The argumentative dimension is expressed in the first part of the question: What do you think? The rest of the sentence is in the epistemic dimension, which assumes conceptual retrieval. It is important that during student discussion, they pay attention to the possibility of understanding the word correlated as common sense and relate it to the statistical sense.

\section{ANALYSIS}

We initiate the analysis with an overview of the groups' answers, which we present in Table 3 , and we emphasize that we tried to keep the (in)formality or statistical language used in the students' writings, altering only what was strictly necessary to allow for readability.

Table 3. Answers provided by groups

Item 3 question: What do you think of the sentence: "Variables are non-correlated, and therefore are independent"?

G1 The implication is not completely true since a lack of correlation does not imply that they are independent. It only indicates that they do not present a linear correlation.

G2 If the sense of correlation mentioned in the question is exclusively of the linear correlation type, then the sentence is false because variables may have some other types of relation. If the sense of correlation represents any type of relation, then the sentence is true.

G3 If we think of the Portuguese language, then the sentence seems to make sense. But if we think of the language of Statistics, the sentence is not valid. When we consider variables that are not correlated as having null correlation coefficient, we couldn't, simply by the fact that it is null, conclude that the variables are independent. However, the contrary is also valid, since independent variables have null correlation coefficients.

G4 The sentence is incorrect! Variables that do not correlate can be independent or not, since correlation can be null if $\mathrm{E}(\mathrm{X}) \mathrm{E}(\mathrm{Y})=\mathrm{E}(\mathrm{XY})$, and this does not imply independence. The reverse, however, is valid. When variables are independent, correlation is null, because, in the case of independence, $\mathrm{E}(\mathrm{X}) \mathrm{E}(\mathrm{Y})$ is always equal $\mathrm{E}(\mathrm{XY})$.

G5 We disagree, bearing in mind that correlation $=0$ means that there is no relationship. We have $\operatorname{Cor}(X, Y)=\operatorname{Cov}(X, Y) /\left(\sigma_{X} \sigma_{Y}\right)$. Being independent implies a covariance of 0 , but the reverse is not true, since dependent variables can obtain covariance $=0$. As we have said, $\operatorname{Cor}(X, Y)$ $=\operatorname{Cov}(\mathrm{X}, \mathrm{Y}) /\left(\sigma_{\mathrm{X}} \sigma_{\mathrm{Y}}\right)$. We conclude that being independent implies that $\operatorname{Cor}(\mathrm{X}, \mathrm{Y})$ is 0 , but not the reverse (the given sentence).

G6 We believe that if variables are not correlated when covariance is zero, then they are independent.

G7 The sentence is false because linear correlation is equal to zero when covariance is zero, and a covariance that is zero does not necessarily indicate independence between variables. When covariance is zero, there is no necessary independence, however, when variables are independent, covariance is zero. Besides, there are different ways for variable correlation, not only the linear case.

G8 We know that $\rho(X, Y)=\operatorname{cov}(X, Y) /\left(\sigma_{X} \sigma_{Y}\right)$, and that ind variables $\Rightarrow \operatorname{cov}(X, Y)=0$, therefore, they are not correlated, but if not correlated $\nRightarrow$ independent, thus, the sentence is incorrect.

G9 The implication is not valid (if non-correlated $\rightarrow$ independent), but the implication (independent $\rightarrow$ non-correlated variables) is true.

Source: Designed by the authors

Most groups recovered the statistical concept that is encompassed in the question. However, only some (Groups 2 and 3) mentioned the informal use of the word correlation. Groups 4, 5 and 8 responses 
were quite technical, and presented formulas to support their arguments. Group 6, despite interpreting correctly what non-correlated meant, was incorrect in their conclusion.

In the following two subsections, we will analyze each of the two phases of the Discussion Circle separately. Data analysis was conducted to focus on linguistic-discursive choices and on the statistical contents the participants used to interact with their peers. It includes their points of view, agreement and discordance to others and the arguments they used to jointly come to a shared response. The discourse analysis revealed how the students critically and collaboratively constructed a shared meaning negotiation.

\subsection{DISCUSSION CIRCLE: ANALYSIS OF THE GROUP DISCUSSIONS}

In this subsection, the group discussion audios will be analyzed. As previously indicated, we restricted our analysis to some groups, that is, Groups 2, 3, 6, 7 and 9. When necessary, we will refer to the answers provided in Table 3.

Group 2. The group was composed of four participants, and initiated the discussion with the students interacting, trying to understand the sentence and seeking to explain to each other the sense of the terms that composed the problem:

2C So, he needs to say what type. I'll ask him what type of correlation it is. If it is the linear type ... wait a minute.

2D: "No, they aren't". Isn't a little ambiguous? They aren't.

2B: Because it's like ... the idea is that they are, and the non-correlated is not only type

$\cdots$

2D: Oh, it is as if there were a hyphen, but there isn't one.

2B: That's it, they are not correlated. Do you understand?

2A They are correlated and non-correlated.

2D This sentence is a little ambiguous, "they are non-correlated". Ok. "What do you think of the sentence ..."

2B: Ambiguous ...

2A It's not ambiguous, is it? It is contradictory ... I don't know.

2B: It's not ambiguous. All right. So, variables are non-correlated.

2A: We are discussing the structure of the sentence.

2D: Forget it, continue. She has already gone to logic.

2B: Continue.

2D: Variables are not correlated; therefore they are independent, is that it?

2A: Ah! "they are non-correlated", understood.

2D: In other words, they are not ...

2A: Are not correlated.

2D: Are not correlated.

2C: No, but this was what we were really talking about because look ... here we can consider ... if this correlation that is defined in the question is of the linear type, not necessarily, because they can have other types of dependencies. If this correlation that is defined in the question is any other type of correlation, then yes. Because if they do not correlate in any way, they will be independent.

The above excerpt begins and ends with utterances by student $2 \mathrm{C}$, who seemed to be more certain of the answer provided. Between these two utterances, we can see the development of reasoning if we look at sentences uttered by students 2A, 2B and 2D. Following that, the group members entered the discussion about the meaning of correlation and seemed to be in doubt about the logic of the sentence. After the excerpt transcribed below, the group members made a few extra comments and prepared the answer.

2C: If this word is restricted solely to linear correlation, the sentence is false because it is restricted. So, there may be another case that proves this sentence to be false, right? Now, if the word encompasses all the possible cases, then it is true because there is no case that deviates. 
2B: The linear.

2C: $\quad$ The linear is included.

2D: But then it is not false here. It is true.

2C: Look. All right. So I don't know what you want to write as the answer.

2D: No, it doesn't matter either way; I just want to understand.

2B: Yes. We want to understand.

2D: You just said it.

2C: The sentence is false. The sentence.

2D: So, the sentence is false. This is what I mean, but if ... if the idea of correlation is to represent any other type of relation ...

2C: Not any other type; any type, including the linear.

2D: Ok, that's alright, any type of relation ... if you are including the linear correlation, the linear can occur on its own, so, the sentence will be false. Therefore, I cannot say that any other type, together with the linear type will be true. This is our ...

Both excerpts presented suggest that the language of argumentation and collaboration was central to building the answer. As pointed out by Vygotsky, human development is a collaborative project that assumes a social practice in which participants act by means of a constant mutual and recursive process of concept construction. It is what we see in the relations of this group in which participants speak collaboratively, one continuing the other's speech, expanding, resuming what was said and questioning what their peers said. Hence, doubts and understandings are placed and discussed, creating a ZPD that allowed them to critically query the other participants' understandings in order to construct an answer. The writing of the answer presented (Table 3) indicated clarity about the statistical concept of correlation and also mentions its informal use.

Group 3. The group had five members and their answer demonstrated the correct understanding of linear correlation. The answer mentioned a possible non-technical sense in Portuguese for the word correlation and indicated that the reverse implication would be true. The group discussion was initiated with an understanding of the sentence, and evolved to a conclusion, as we can see from the excerpt of transcribed dialogue below.

3C: Yes, yes, it's true. It can't be like that; it has to be independent after not been correlated.

3D: Yes. That's it.

3C: I see.

3D: So it's the contrary of this sentence that is correct, right?

3C: The reverse of the sentence is what?

3D: If they are independent, then the variables are not correlated, but if they are not correlated it doesn't imply saying that they are independent. Is that it?

3A: If it is about coefficient correlation ...

3C: If you correlate and it is equal to zero, it doesn't necessarily mean that they are independent or not.

3A: In terms of Portuguese, you can conclude that...

3B: No. She concluded.

3A: By using Portuguese, not statistics.

3D: That it is true, right?

3A: Is it true? But if we think of the coefficient ...

3D: That the reverse is true.

3B: Say that it is false and the reverse is true.

3D: Yes, the reverse is true.

3B: In other words, ...

3C: Because in terms of Portuguese, it really is true.

3D: Yes, the reverse in terms of Portuguese is true as well. Now, in terms of statistics, only the reverse is true. So, it is only the reverse.

Like the other, this group created a critical-collaborative process in which they stated what they understood and retrieved the concept. Besides, they also brought to the discussion the daily, spontaneous understanding of correlation, distinguishing it from the statistic concept. The interaction 
revealed that the question allowed for a construction of ZPD in which, mediated by the understanding of the statistic concept, participants rapidly reached the answer they constructed.

Group 6. The group was comprised of six students, and their answer showed clarity of the concepts worked in the activity. In some moments, they mentioned the correct interpretation of the concept of linear correlation. However, this did not prevail in the group discussion. As we can see from the excerpt of the audio transcription, several members tried to exemplify so as to be certain of the statements. They had difficulty working in the abstract mode with the concepts involved in the question and pursued an example, but in the end, they are confused and could not structure it.

6B: If variables are independent, they don't necessarily have correlation. But if they do not have linear correlation, it doesn't mean that they are independent as ...

6C: The isn't the formula of the equation that one $\mathrm{E}(\mathrm{XY})$ minus $\mathrm{E}(\mathrm{X}) \mathrm{E}(\mathrm{Y})$ ?

6B: Forget the formula, think only of the concept. Linear correlation will give you the notion of how the two variables ... if they are ...

6D: If they are independent, it could happen, but this doesn't imply that they (are) independent for this.

6B: If they have linear relationship, they are dependent. So, the reverse cannot be false, if they are independent, the variables are not correlated. Now, if they are not correlated, they are independent .... not necessarily.

6A: Not being correlated does not imply that they are independent, do you agree? I don't know.

6B: I agree.

6A: I was thinking about an example so as to better clarify.

6C: It's just that, an example to talk about correlation is sort of hard, isn't it? Because correlation requires calculation ... for us to know.

6B: I don't know, let's get like two events ... two interdependent events, imagine 2 independent events ... $\mathrm{X}$ and $\mathrm{Y}$, and the probability of $\mathrm{X}$ and $\mathrm{Y}$ occurring is not the multiplication of probabilities ... when they are non-correlated, they are independent. Imagine a case in which correlation is zero.

6A: List $\mathrm{D}$, list $\mathrm{D}$ was equal zero. We had to find variation of $\mathrm{X}$, variation of $\mathrm{Y}$ and variation of the sum of $\mathrm{X}$ and $\mathrm{Y}$.

6B: Exactly. But the elements were not independent.

6A: We built a table.

6B: Ah! Terrible example then.

6A: Cancel it.

6D: By looking at the structure of the correlation formula itself we can see that if it is zero, it is independent.

6C: If it is independent, it is zero, but not necessarily the contrary is the same, because the issue of dependence is that ... each part of $\mathrm{X}$ and $\mathrm{Y} \ldots$... that's how we think independence.

6D: Yes.

6A: We would have to get a case in which they are independent, but that example is a bad one. I think that in terms of conversation this is enough, considering how much we have talked. When we go to the writing part, we think of an example.

Interaction in Group 6 revealed a process of concept construction in which participants' utterances were mediated by their experiences in the classroom involving a list of exercises and tables that had been completed. They constructed a collaborative and recursive process of suggestions, rejected ideas and attempted to construct an example that would allow them to answer the question. Hence, when they were writing their answer, we noticed from the audio recording that one of the members of the group was drawing a graph with two variables on the Cartesian axes with a view to achieving greater clarification. From that moment on, they tried to argue about independence and linear correlation, and after several questions, the group was unable to come up with an example that satisfied every one, thus deciding for the (incorrect) writing that was previously presented on Table 3.

Group 7. With four participants, Group 7 answered the question precisely, from the statistics point of view, and the audio recording transcript, which is presented below, shows that they seemed to be clear about the concepts discussed. However, they did not mention any other possible interpretation, from the perspective of Portuguese, for the word correlation. This may have occurred due to the search for 
objectivity in their answer or, perhaps, because they wished to restrict the answer purely to the statistics context. In this case, it indicated a limitation in the group's reflection.

7A: Question 3, "What do you think of the sentence "variables are not correlated, therefore, they are independent"?

7B: I think that ...

7A: It's wrong.

7B: Do you remember that he spoke about the ... like, it only shows that they are not linearly dependent, but they might have other types of dependency.

7C: In the list (of activities), there was a case in which variables were dependent, but in the sense that $\ldots$

7A: And algebraically analyzing, if the correlation is zero, it's because the covariant is zero and the covariance can be zero, but not necessarily independent.

7D: If they are independent, the covariant is zero, but if the covariant is zero, they are not independent.

7B: That's it; we can write it down.

The answer was constructed by all participants. It involved a critical-collaborative relation mediated by the memory of classroom experiences (exercises and the professor's speeches), in order to recover the concept of linear correlation and answer the question.

Group 9. The answer formulated by Group 9 was similar to that of Group 7. Nonetheless, according to the audio recording transcription that follows, Group 9 seemed to be more heterogenous than Group 7 when it came to the mastery of the subject matter. They began the discussion with one of them saying they were always confused by the matter, and, after several interventions, including a memory retrieval of the exercise that they did in class, they got to the answer, which is presented on Table 3 . The group was comprised of seven students, but two of them did not take part in the discussion.

9A: "What do you think of the sentence: "Variables are non-correlated, and therefore are independent"?"

9B: This is something that still puzzles me, Bro.

9C: Do you have this doubt since you were a kid?

9A: I think he meant that the variables do not correlate, therefore, they are independent. This is interesting because in the correlation formula it is covariance by standard deviation. And if covariance is zero, this means that they are independent... if covariance is zero, the correlation coefficient is also zero. So, there is logic in it; if variables are not correlated, i.e., correlation coefficient is zero, if they do not correlate, they are independent.

9C: But if ... as we discussed in question 1, in the case variables are independent or not independent, and the intersection is actually the multiplication?

9A: Coincidences?

9C: Yes, if it coincides as if they were independent, but they are not?

9B: Like, you already see that they are not independent, but when you start, for example, to calculate the covariance, the covariance is zero in the end.

9D: Correlation is going to be zero.

9C: Has this happened before?

9B: It happened; we did an exercise and this was the result.

9A: We did exercise 3d. The correlation was zero, even though variables $\mathrm{X}$ and $\mathrm{Y}$ are not independent, because of two dice that we were rolling, which were the sum and the number of faces with number 2 .

9E: So, in this case, it wouldn't have this result. We have to understand when they are and when they are not.

9B: He says here that variables are not correlated, therefore, they are independent. What if we said the opposite? If they are independent, they are not correlated.

9E: But in every case.

9A: Yes, because in every case that it is independent, the covariance will be zero, and so will the correlation.

9C: It makes sense.

9B: Is it like a one-way situation?

9A: Yes. So, we can convert this sentence so that it becomes true. 
9E: We can say that independent implies non-correlated, but non-correlated does not imply independence.

9C: Yes, I think that's it.

This group organized an interactional space in which they could question points of view. Mediated by the retrieval of concept understandings, previous lessons and exercises completed before, they designed the answer which is stated in Table 3.

To conclude this section, we can say that the question asked in Item 3 allowed for the argumentative organization of language and a critical-collaborative context to answer what had been requested. This involved the presentation of points of view, arguments based on the retrieval of the concept understanding, in order for them to accept or refuse suggestion, which became an intertwining of voices. In the final consideration these matters will be revisited.

\subsection{DISCUSSION CIRCLE: ANALYSIS OF THE WHOLE CLASS DISCUSSION}

The second phase of the Discussion Circle was quite hindered due to availability of time. Initially, the time set aside for this phase was 20 minutes for the three items. This proved insufficient and the lack of time favored, to a certain degree, the silencing of students. Besides, because it was carried out during the last lesson before the test, the professor was pressured to complete the explanation of the curricular content, clarifying doubts that might have emerged in the groups. Therefore, in the general discussion, Item 3 took approximately 5 minutes of the overall time.

When beginning the discussion of this item, the professor chose one of the groups and read the answer they had written and handed in. After that, he requested comments from students, as per the audio recording transcript that follows:

Professor: Question: What do you think of the sentence: "Variables are non-correlated, and therefore are independent?" Answer (written by one of the groups): "the implication is not totally true because a non-correlation does not imply that they are independent because it only indicates that they do not present a linear correlation." So? ... What do you think ... of this answer?

Student 1: $\quad$ My group added a little something extra.

Professor: I'm listening ...

Student 1: The group sort of talked about the reverse, you know? The answer is only discussing the implication and we talked about the reverse as well ... to us, when they are independent, it implies that the variables are not correlated.

Professor: Ok, it's correct.

Student 1: $\quad$ And that's where we got.

Professor: What else?

Student 2: We also talked about the fact that they are not (correlated). They cannot have a linear relation; they can have another kind of relation, exponential relation or something like that, but in this case, if the word correlated is used in a broader sense, covering all possible relations, the sentence would be ... we kept discussing if the sentence would be correct in this case, I mean ... if the ... if there was not any type of relation, then, in that case, they would be independent. But only if the word correlated did not cover solely the linear case, but all the possible relations.

Professor: $\quad$ Ok. And? Who else? The groups? The card folks? The little card folks have not said anything yet. What do the hive troop have to say? (mention to groups of a prior activity)

Student 3: We said the same thing. Actually, the reverse is true. They are independent in relations ..., but the contrary is not true because even if the value is zero, they can be dependent. The expected value of $\mathrm{X}$ times $\mathrm{Y}$ is the same value as the expected value of $\mathrm{X}$ times the expected value of $Y$, even if they are dependent can occurr...

Professor: $\quad$ OK, any other comment, people?

As we have verified from the audio recording transcribed, the interaction was limited to three participants who brought contributions from their groups. The first student completed the sentence initially read and the other two mentioned additional aspects that they understood could be part of the answer. 
During the discussion, the professor's action was limited to reading and requesting responses that could move the understanding of the concept of correlation forward, which, in fact did occur, and the main aspects related to the concept were mentioned but were not discussed for lack of time. At the end of the activity, the professor resumed the key ideas of the concept of linear correlation and the social (or cultural) use of the term correlation (not transcribed from the audio recording). We therefore experienced a difficulty that is common to large groups. The students who had less conceptual lucidity did not feel comfortable to intervene and exhibit their doubts, which was less evident in the smaller groups. Again, in this particular situation, an important aspect to be considered was the time that was available, since the class was close to the end, and many students had other commitments.

\section{FINAL CONSIDERATIONS}

As discussed in Section 2 (Theoretical Framework), researchers in the field of statistic education emphasized, among other aspects, the need for a greater stress on the understanding of concepts rather than on calculations. Several of these researchers contributed to the development of statistal literacy in introductory courses of statistics and included theoretical-methodological suggestions. A theoreticalpractical approach is important so that students can appropriate the concepts and their usage in social practices, both in schools and beyond the school walls. Especially, in courses of statistics taken in undergraduate programs by students who will work with Basic Education Mathematics the use of activities that may also be carried out by these teachers with their future students is essential. One of them, and maybe the main one, is the one that encompasses the use of data collected by the students themselves, which some authors call project activity (in more than one variety). This paper suggested Discussion Circle activity, which can be added, at any school level, to other initiatives already planned by the teacher. Furthermore, in teacher education programs, this activity can contribute to the development of new teaching practices.

Supported by Vygotsky's works $(1930,1934)$, we discussed the key role of the organization of conceptual discussions in smaller groups, especially when dealing with large classrooms of students. Two reasons are highlighted here: the possibility of enabling every student to take part criticallycollaboratively in the construction of the concept by means of argumentation, and the possibility of understanding, from the part of the teacher, of where the students are in greater need of support.

Interaction in smaller groups was a collective formation that, by means of mutual and dialectic relations, discussed the construction/retrieval of the focused concept, whilst being mediated by different cultural artifacts such as the professor's discussion in the classroom, tables and exercises that were completed. It is a space organization in which through collaborating with others, the students put forth their doubts and reasoning, which often differed from those of their peers. In this process, they learned and developed new ways to argumentatively reason, act and intervene in each other's speeches (with theoretical support).

When carrying out the activity of Discussion Circle that was discussed in this paper, some groups had too many members and this resulted in the silencing of some students during the discussion. In groups where there were three to five members, we rarely saw a member that did not take part in the debate. The professor must pay attention to this matter during the formation of groups. Another important factor is the time available for the activity-this impacts the development of conceptual understanding during both phases (group work and whole class discussion). If there is little time, students who are less prepared will avoid asking questions, while those who are better prepared will often take the lead by presenting a conclusive answer, frequently taking the role of the professor. In our case, we had a limited amount of time for the whole class discussion, and this may have been the main reason for having poor participation of the students in that part of the activity.

Despite the difficulties mentioned above, the excerpts that we presented in this paper suggest a movement of perception, participation, and self-reflection that assumed a collaborative, reflective, and recursive practice involving contradiction between the several senses that the participants brought to the lesson as to the object under discussion. As discussed by Ninin (2018), the epistemic-argumentative dimension of the question asked by the professor allowed for dialogical expansion, validation of the (critical) argumentative space for discussion, and collaboration as to the production of scientific knowledge. Hence, comparing the initial opinions of some participants with answers presented by the 
groups, we can say that the activity carried out allowed for the conceptual development of several students.

Discussion Circle seemed to contribute to the teaching-learning process and that of student development. Its use by teachers in their classrooms can be paced, perhaps beginning with one single item for discussion. By doing so, the teacher and the students slowly become more familiar with the procedures that are involved in the activity. Students learn to listen to their peers and to organize questions that are argumentative whilst requesting clarification, expansion, and justification from colleagues. The teacher acts by means of questions rather than answers in order to allow the students to reveal their points of view and the argumentative support for their answers.

Using this activity, as we have reported in this paper, is not the only way to use Discussion Circle. For example, for concepts that have not yet been presented in classroom, students may read texts and or even discuss their spontaneous knowledge about a certain topic. After that, during the whole class discussion, knowledge can be systematized. The teacher and students create ZDP through dialogical discourse, which allows participants to collaboratively build new knowledge. The mediation in this case is in the organization of the teacher's questions and in the students' arguments, during the dialogues to negotiate a solution to the question posed.

Despite several economic, educational, and cultural differences among countries, whether in Latin America or around the world, similar students' difficulties are reported by the statistics education research community. Fundamental statistical topics such as distinction between independent and disjoint events, difference between empirical and model distributions, interpretation of confidence intervals, limits of hypothesis testing decisions, among others, can all be worked out through the Discussion Circle, since it can be used in different teaching-learning approaches and school grades. In short, Discussion Circle is an instrument to develop statistical reasoning at all educational levels.

There is no magical formula for learning or development success because they require commitment, dedication and use of methodologies that focus on critical-collaborative participation of students. Statistics education has already produced several alternatives that need, however, to reach a larger number of teachers, especially those in elementary, mid, and high school education. Further than that, just a simple suggestion: allowing the students voices in school activities is an essential path for autonomous construction and intellectual development.

\section{REFERENCES}

Barbosa, M. T. S., Velasque, L. S., \& Silva, A. S. (2016). O letramento estatístico na formação dos professores: um tutorial metodológico. [Statistical literacy in teacher education: A methodological tutorial] VIDYA, 36(2), 397-408.

Brasil Ministério da Educação \& Secretaria de Educação Fundamental. (1997). Parâmetros Curriculares Nacionais Ensino Fundamental. Ensino de primeira à quarta série. [National curricular parameters for elementary education: From 1st to 4th grades] MEC/SEF.

Brasil. (1998). Ministério da Educação. Secretaria de Educação Fundamental. Parâmetros Curriculares Nacionais Ensino Fundamental. Ensino de quinta à oitava série. [National curricular parameters for elementary education: From 5th to 8th grades] MEC/SEF.

Brasil Ministério da Educação. Secretaria de Educação Média e Tecnológica. (2000). Parâmetros Curriculares Nacionais. [National curricular parameters] MEC.

Brasil Ministério da Educação. Secretaria da Educação Média e Tecnológica. (2002). Parâmetros Curriculares Nacionais + Ciências da Natureza e suas Tecnologias [National curricular parameters + Natural sciences and technology]. MEC.

Brasil Ministério da Educação. Governo Federal. (2018). Base nacional comum curricular. [Common national curricular basis] MEC. http://basenacionalcomum.mec.gov.br/

Biehler, R., Frischemeier, D., Reading, C., \& Shaughnessy, J. M. (2018). Reasoning about data. In D. Ben-Zvi, K. Makar, \& J. Garfield (Eds.), International handbook of research in statistics education (pp. 139-192). Springer.

Campos, C. R., Wodewotzi, M. L. L., \& Jacobini, O. R. (2011). Educação Estatística-teoria e prática em ambientes de modelagem matemática. [Statistic education: Theory and practice in environments of mathematical modelling] Autêntica.

Freire, P. (1978). Pedagogia do oprimido. [Pedagogy of the oppressed] Paz e Terra. 
GAISE College Report ASA Revision Committee. (2016). Guidelines for assessment and instruction in statistics education: College report. American Statistical Association. www.amstat.org/asa/files/pdfs/GAISE/GaiseCollege_Full.pdf

Gal, I. (2002). Adults' statistical literacy: Meanings, components, responsibilities. International Statistical Review, 70(1), 1-25.

Garfield, J. B., \& Ben-Zvi, D. (2008). Developing students statistical reasoning: Connecting research and teaching practice. Springer.

Gee, J. P. (2000). New people in new worlds: Networks, the new capitalism and schools. In B. Cope \& M. Kalantzis (Eds.), Multiliteracies: Literacy learning and the design of social futures (pp. 41-67). Routledge.

Holzman, L. (2002). Vygotsky's zone of proximal development: The human activity zone. Presentation to the Annual Meeting of the American Psychological Association, Chicago.

https://www.eastsideinstitute.org/wp-content/uploads/2014/05/Vygostskys-Zone-of-ProximalDevelopment.pdf

Kalantzis, M., \& Cope, B. (2008). Introduction: Initial development of the 'multiliteracies' concept. In S. May \& N. Hornberger (Eds.), Language education and multiliteracies. Encyclopedia of language and education, 2nd ed., Vol. 1: Language policy and political issues in education (pp. 195-212). Springer.

Magalhães, M. C. C. (2009). O método para Vygotsky: Zona proximal de desenvolvimento como zona de colaboração e criticidade criativas. [The method for Vygotsky: Zone of Proximal Development as zone of collaboration and creative criticality] In R. H. Schettini et al. (Eds.), Vygotsky: Uma revisita no início do século XXI [Vygotsky: Revisit in the early XXI Century] (pp. 53-78). Andross.

Magalhães, M. C. C. (2018). Formação contínua de professores: a organização crítico-colaborativa para transformação. [Continuous teacher education: Critical-collaborative organization for transformation] Linguagem: Estudos e Pesquisas [Language: Studies and Research, 22(2), 17-35.

Magalhães, M. N. (2019). Itens dissertativos em avaliações. [Argumentative items in assessments] In C. E. Lopes, M. Porciúncula, \& S. Samá (Eds.), Perspectivas para o ensino e a aprendizagem de Estatística e Probabilidade. [Perspectives for the teaching and learning of statistics and probability] (pp. 297-316). Mercado de Letras.

Magalhães, M. N., \& Lima, A. C. P. (2015). Noções de Probabilidade e Estatística. [Notions of probability and statistics] $7^{\mathrm{a}}$ Edição, $3^{\mathrm{a}}$ reimpressão revista. Edusp (Original work published 1999).

Magalhães, M. N., \& Magalhães, M. C. C. (2014). A critical understanding and transformation of an initial statistics course. Statistics Education Research Journal, 13(2), 28-41. https://doi.org/10.52041/serj.v13i2.278

Ninin, M. O. G. (2018). Da pergunta como ato monológico avaliativo à pergunta como espaço para expansão dialógica - uma investigação à luz da Linguística Aplicada sobre modos de perguntar. [From questions as assessment monologues to questions as a space for dialogical expansion: An investigation under the light of applied linguistics about questions] $2^{\mathrm{a}}$ Edição, revista e ampliada. Pontes Editores.

Ninin, M. O. G., \& Magalhães, M. C. C. (2017). A linguagem da colaboração crítica no desenvolvimento da agência de professores de Ensino Médio em serviço. [Language of critical collaboration for in-service development of high school teachers' agency] Alfa, 61(3), 625-652. http://www.scielo.br/pdf/alfa/v61n3/0002-5216-alfa-61-03-0625.pdf

Ponte, J. P., \& Noll, J. (2018). Building capacity in statistics teacher education. In D. Ben-Zvi, K. Makar, \& J. Garfield (Eds.), International handbook of research in statistics education (pp. 433456). Springer.

Porciúncula, M., \& Samá, S. (2015). Projetos de aprendizagem: uma proposta pedagógica para a sala de aula de estatística. [Learning projects: A pedagogical proposal for statistics classrooms] In S. Samá, \& M. Porciúncula (Eds.), Educação estatística: ações e estratégias pedagógicas no Ensino Básico e Superior [Statistics education: Pedagogical actions and strategies in primary and tertiary teaching] (pp. 133-141). CRV.

Samá, S., Cazorla, I., \& Amorim, M. É. (2019). Metodologias ativas no ensino de Estatística nos cursos de Licenciatura [Active methodologies for the teaching of statistics in teaching programs]. In C. E. Lopes, M. Porciúncula, \& S. Samá (Eds.), Perspectivas para o ensino e a aprendizagem de 
Estatística e Probabilidade [Perspectives for the teaching and learning of statistics and probability] (pp. 195-220). Mercado de Letras.

Schreiber, K. P., \& Porciúncula, M. (2019). Projetos de aprendizagem no desenvolvimento profissional do professor de Matemática para o ensino de Estatística [Learning development projects of the mathematics teacher for the teaching of statistics]. In C. E. Lopes, M. Porciúncula \& S. Samá (Eds.), Perspectivas para o ensino e a aprendizagem de Estatística e Probabilidade [Perspectives for the teaching and learning of statistics and probability] (pp. 221-246). Mercado de Letras.

Stetsenko, A. (2017). The transformative mind: Expanding Vygotsky's approach to development and education. Cambridge University Press.

Vygotsky, L. S. (2001). A Construção do Pensamento e da Linguagem. [The construction of thought and language] Martins Fontes (Original work published 1934).

Vygotsky, L. S. (1999). Tool and sign in the development of the child. In R. Rieber (Ed.), The collected works of L. S. Vygotsky. Kluwer Academic/Plenum Publishers (Original work published 1930).

Wild, C., \& Pfannkuch, M. (1999). Statistical thinking in empirical enquiry. International Statistical Review, 6(3), 223-265.

MARCOS N. MAGALHÃES

Department of Statistics

Mathematics and Statistics Institute

University of São Paulo

1010, Matão Street - postcode 05508-090

São Paulo, SP, Brazil 